\title{
PRAKTEK PEKERJAAN SOSIAL BAGI "STIGMATIZED GROUP": UPAYA MEWUJUDKAN KESERASIAN SOSIAL BERBASIS HAM DAN PENDIDIKAN MULTIKULTURAL
}

\author{
OLEH: \\ SITI NAPSIYAH ARIEFUZZAMAN ${ }^{1}$, S.AG.BSW.MSW
}

1 Dosen Program Studi Kesejahteraan Sosial UIN Jakarta

\begin{abstract}
Abstrak
Kelompok terstigmatisasi (stigmatized group) merupakan kelompok orang yang memiliki pengalaman diskriminasi dan eksklusi di masyarakat karena stigma yang dilekatkan kepada mereka. Stigma negatif yang diarahkan kepada kelopok ini beragam latar belakangnya: fisik, status ekonomi, identitas social, dan sebagainya. Bagaimana kelompok ini bertahan di masyarakat, dan apa yang harus dilakukan oleh pekerja social untuk membantu kelompok ini agar bisa keluar dari masalah yang dihadapi di masyarakat.

Tulisan ini berusaha menjelaskan tentang pengalaman terstigmatisai di kalangan anak-anak dari keluarga terduga dan terpidana kasus terorisme. Kelompok ini mendapatkan stigma sebagai "anak teroris". Stigma tersebut menjadikan anak-anak mengalami eksklusi social dan diskriminasi di masyarakat. Dampaknya anak-anak dari keluarga ini semakin "eksklusif" di masyarakat dan berpotensi untuk tetap berada dalam rantai jaringan kelompok "radikal".

Pekerja social dapat bekerja bersama keluarga terduga dan terpidana kasus terorisme melalui program pendampingan psikososial, pelayanan social berbasis Hak Asasi Manusia (HAM) dan pendidikan multikulturalisme bagi masyarakat atau lingkungan tinggal keluarga. Hal ini karena di antara benih terjadinya aksi gerakan radikal dan teror berasal dari tidak adanya keserasian social di masyarakat.
\end{abstract}

Kata Kunci: Radikal, Stigma, psikososial, eksklusi social, keserasian social,

\begin{abstract}
This study aims to challenge social work practice in Indonesia on anti-discrimination approach, social work practice in multicultural society, human right based approach, and child protection; seeks the need of social service for stigmatized children of terrorist family. They should not be seen as "criminal" instead as a 'victim' who need help from other to disengage from the cycle of terrorist family, link or group; Develops a framework that helps us examine and thereby understand the problem of being stigmatized children and the impact of that stigmatization on children behavior; expected that the findings of this study will help to create new terrorism prevention and intervention in Indonesia.
\end{abstract}


The study shows the experience of children of parents who are "defendant or convict with terrorism" social stigma and social exclusion. They find difficulties to get access to education, social service and other rights. The worst thing from social exclusion is the potential rise of inherited revenge. Although there is no valid number yet about the number of children of terrorist in Indonesia, but it is predicted around 2000 children whom the parent are suspected terrorism, committed terrorism, prisoned, recidivist, or died.

Keywords: radical, stigma, social exclusion, social harmony, psychosocial

\section{Pendahuluan}

Kekerasan social, terorisme konflik sosial berbasis ras, agama, dan syara (RAS) merupakan bentuk kejahatan kemanusiaan yang memiliki dampak dan masalah social di masyarakat. Seperti munculnya trauma, hancurnya sarana publik, bahkan hilangnya nyawa. Jumlah keluarga yang terdampak karena kasus kekerasan sosial dan terorisme terus meningkat di Indonesia. Pemerintah telah melakukan berbagai cara untuk menyelesaikan masalah tersebut. Di antaranya adalah program Keserasian sosial yang dicanangkan oleh Kementerian Sosial Republik Indonesia. Program ini berusaha untuk memberikan dukungan dan program bagi kelompok masyarakat atau budaya tertentu yang sudah mengalami ketertinggalan dalam masyarakat.

Selain itu, pemerintah juga telah membentuk badan khusus yang menangani masalah terorisme, yaitu Badan Nasional Penanggulangan Terorisme (BNPT).Selain itu pemerintah juga telah mengamanahkan Kementerian Hukum dan Hak Asasi Manusia (KemenkumHam RI) untuk membuat

${ }^{4}$ Petrus Golose (2009), mendefinisikan Deradikalisasi sebagai segala upaya untuk menetralisasi paham-paham radikal melalui pendekatan interdisipliner, seperti hukum, psikologi, agama, dan sosial budaya bagi mereka yang dipengaruhi atau terkontaminasi kebijakan dan pembinaan bagi narapidana kasus terorisme baik di Lembaga Pemasyarakatan (lapas) maupun Balai Pemasyarakatan (Bapas).Diantara program untuk mengatasi masalah terorisme adalah program deradikalisasi ${ }^{4}$.Namun fenomena radikalisme, militanisme, premanisme, dan terorisme seakan semakin tumbuh subur di Indonesia.

Program deradikalisasi menuntut keterlibatan semua pihak untuk dapat menjangkau seluruh elemen masyarakat atau kelompok yang dinilai memiliki kerentanan untuk dapat terlibat dalam jaringan atau mengarah kepada kelompok tertentu yang memiliki potensi untuk terlibat dalam aksi terorisme. Hal ini karena di antara akarmunculnya serta masih suburnya konflik, kekerasan social dan terorisme adalah adanya "dosa yang diwariskan" atau "dendam yang diturunkan" dalam keluarga, kelompok, dan masyarakat.

Artikel ini tidak akan membahas secara detail tentang terorisme dan radikalisme di Indonesia. Akan tetapi akan lebih berusaha

paham radikal atau pro-kekerasan. Dalam hal ini mereka termasuk; narapidana, mantan narapidana, individu militan radikal yang pernah terlibat, keluarga, simpatisannya dan masyarakat umum. 
mendiskusikan tentang upaya mewujudkan keserasian social di masyarakat melalui pendekatan kesejahteraan/pekerjaan sosial bagi kelompok terstigmatisasi (stigmatized group) dari kelompok anak-anak dan keluarga dari seorang terduga, terdakwa, terpidana dan mantan narapidana kasus terorisme.

Dalam praktek pekerjaan sosial, ada banyak kelompok rentan yang sangat potensial untuk mendapatkan pelayanan sosial. Pelayanan sosial dalam pengertian yang lebih luas yaitu meliputi aspek kebijakan, program pembinaan, pendampingan, dan pemberdayaan. Di antaranya adalah kelompok anak dan keluarga yang terstigmatisasi secara sosial. Dari sekian kelompok yang paling rentan mengalami stigmatisasi social di masyarakat adalah anak dan keluarga yang lebih sering dikaitkan/lekatkan kepada "istri" atau "orang tua" dari terpidana kasus terorisme. Nasib seorang anak teroris sebagaimana dalam pepatah "sudah jatuh tertimpa tangga pula".

Pekerjaan sosial/kesejahteraan social sebagai sebuah aktivitas (activity) dan profesi (profession) memiliki tanggung jawab untuk memikirkan tentang kebijakan dan program social yang tepat bagi anak yang mengalami stigma social (stigmatized group). Sebagai kelompok yang mendapatkan stigma social (tersitgmatisasi) dalam masyarakat, mereka pasti mengalami kehidupan yang tidak mudah di masyarakat. Akses dan relasi social yang terhambat akan menghambat pertumbuhan dan perkembangan psikologis mereka kelak di kemudian hari.

Hal ini karena pelayanan terhadap anak dan keluarga selama ini lebih banyak ditargetkan kepada mereka yang tergolong sebagai pengemis, anak terlantar, anak korban kekerasan dalam rumah tangga, dan lain-lain tapi masih sangat jarang yang benar-benar menyentuh kepada anak-anak dari keluarga kasus terorisme.Stigma sosial yang dialamatkan kepada anak dan keluarga narapidana teroris semakin menyudutkan keberfungsian sosial mereka di masyarakat.Mereka akan mengalami gangguan kepribadian, dan lain-lain.

Oleh karena itu, artikel ini berusaha untuk mendiskusikan tentang peluang dan tantangan praktek pekerjaan social bagi kelompok yang rentan mendapatkan stigma social sebagai upaya untuk mewujudkan keserasian social di masyarakat. Keserasian social tidak hanya dipahami sebagai sebuah "keseragaman", keharmonisan (harmony), akan tetapi masyarakat yang dinamis, yang beragam (seragam sangat berbeda jauh maknanya dengan beragam), inklusif, dan toleran.Hal ini patut menjadi catatan bersama bahwa gerakan radikalisme, terorisme dan ISIS tidak muncul karena latar belakang idiologi, namun sangat kompleks diantaranya karena factor kesenjangan ekonomi, dan lainlain. Menurut penulis, ini saatnya Negara hadir untuk merebut kembali hati dan simpati keluarga yang selama ini sudah terlanjur dicocokin/diinternasilasi tentang Negara sebagai "thoghut" sebagai pihak yang lepas tanggung jawab terhadap kesejahteraan mereka.

Pada Undang-Undang Nomor 35 Tahun 2014 dijelaskan bahwa hak anak adalah bagian dari hak asasi manusia yang wajib dijamin, dilindungi, dan dipenuhi oleh orang tua, keluarga, masyarakat, negara, pemerintah, dan pemerintah daerah.

Selain itu pada pasal 59 dijelaskan bahwa perlindungan khusus kepada anak sebagaimana dimaksud pada ayat (1) diberikan kepada: (a) anak dalam situasi darurat; (b) anak yang berhadapan dengan hukum; (c) anak dari kelompok minoritas dan terisolasi; (d) anak 
yang dieksploitasi secara ekonomi dan/atau seksual; (e) anak yang menjadi korban penyalahgunaan narkotika, alkohol, psikotropika, dan zat adiktif lainnya; (f) anak yang menjadi korban pornografi; (g) anak dengan HIV/AIDS; (h) anak korban penculikan, penjualan, dan/atau perdagangan; (i) anak korban kekerasan fisik dan/atau psikis; (j) anak korban kejahatan seksual; (k) anak korban jaringan terorisme. ${ }^{5}$

\section{A. Sekilas tentang Program Keserasian Sosial Kementerian Sosial Republik Indonesia}

Keserasian sosial yang dicanangkan oleh Kementerian Sosial Republik Indonesia sebagai bagian dari penguatan Negara Kesatuan Republik Indonesia (NKRI) merupakan keadaan dan proses kehidupan bersama. Tujuan keserasian social diantaranya adalah membangun, memantapkan dan mengembangkan serta memelihara kembali kehidupan bersama diantara masyarakat di lokasi domisili dalam persaudaraan sejati, kebersamaan, senasib sepenanggungan, saling setia satu dengan yang lain serta solideritas sesama warga masyarakat. Sedangkan tujuan dari keserasian social berbasis masyarakat adalah mewujudkan integarsi social, penerimaan social dalam tatanan hidup berdampingan secara damai melalui sistim dan mekanisme kerukunan sosial diantara kelompok masyarakat yang bertikai. ${ }^{6}$

\footnotetext{
${ }^{5}$ Undang-Undang Republik Indonesia Nomor 35 Tahun 2014 tentang Perubahan atas Undang-undang Nomor 23 Tahun 2002 tentang Perlindungan Anak. Diakses melalui situs KPAI

http://www.kpai.go.id/files/2013/09/uu-nomor-35tahun-2014-tentang-perubahan-uu-pa.pdf
}

Sebagai payung hukum dari program keserasian social adalah Undang-Undang Nomor 7 Tahun 2012 tentang Penanganan Konflik Sosial.Dalam UU ini dijelaskan bahwa ketika terjadi konflik social, maka pranata social dan adat mengedepankan kearifan lokal.Hingga saat ini, Kementerian Sosial telah memetakan daerah rawan konflik social.Terdapat 143 Kabupaten Kota yang terindikasi rawan social, yang sudah diintervensi sebanyak 131 Kabupaten/Kota. ${ }^{7}$

Menurut fungsinya program keserasian social adalah membaurkan kembali para korban bencana sosial dengan masyarakat dalam sistim kehidupan bersama, kerukunan dan berdampingan secara damai, mempercepat adaptasi serta memelihara dan memantapkan sistem kerukunan sosial yang dilandasi dengan semangat non diskriminasi, kesamaan hak dan kewajiban, kesepakatan bersama, non prasangka dan berkelanjutan.

Program keserasian social memiliki nilai dasar yang harus dijadikan pedoman kerja, yaitu:

1. Keseimbangan, keselarasan dan keharmonisan, artinya kegiatankeserasian sosial dilakukan untuk mewujudkan sebuah kehidupanbersama yang selaras, seimbang dan harmonissehingga terwujudmasyarakat yang damai.

2. Mutualitas, artinya keserasian sosial akan terpelihara bilamanakegiatan yang diusulkan merupakan kesepakatan

\footnotetext{
${ }^{6}$ Disarikan dari dari situs Republika onlinehttp://www.republika.co.id/berita/nasional/umum /15/12/31/o0723y365-mensos-program-keserasiansosial-jangkau-520-desa
}

${ }^{7}$ Program Keserasian Sosial KEmenterian Sosial http://metrotevenews.com 
bersama, tidakmerugikan salah satu pihak dan saling menguntungkan.

3. Kesetaraan, artinya bahwa setiap kegiatan keserasian sosial didasarkanpada non diskriminasi, tidak berprasangka dan menghindarkan dirimemberikan labeling kepada kelompok lain, setiap pihak mempunyaikedudukan yang ama pada setiap proses.

4. Kesepakatan bersama artinya setiap kegiatan keserasian sosialmerupakan konsesus bersama atau kesepakatan bersama.

5. Inisiatif bersama, artinya keserasiann sosial yang dikembangkandilingkungan masyarakat didasarkan pada prakarsa dari bawah.

6. Keberlanjutan, artinya bahwa kegiatan keserasian dilakukan secaraberkelanjutan dengan menggali sumber-sumber pembiayaan dariswadaya masyarakat.

Menteri Sosial Khofifah Indar Parawansa menjelaskan tentang program keserasian sosial saat ini sudah menjangkau 520 desa di 136 kabupaten dan 21 provinsi. Menurut Khofifah, untuk menjangkau permasalahan sosial di masyarakat akan lebih efektif jika mendidik sumberdaya manusia dari lingkungan sekitar. Diharapkan, forum yang sudah terbentuk di kecamatan akan menjadi contoh di desa dan menyebar ke kecamatan di sekitarnya. Hal ini karena Indonesia terdiri dari suku dan budaya maka akan memungkinkan munculnya dinamika yang tidak jarang bahkan melahirkan gesekan hingga timbul konflik baik sosial, ekonomi maupun agama. Forum keserasian sosial akan berfungsi untuk menjangkau berbagai kebutuhan teknis masyarakat yang paling kecil seperti kebutuhan akan sarana kegiatan olahraga, dan lainnya. Khofifah mengatakan, tiap titik program tersebut dibantu anggaran sebesar Rp 109 juta.
Bentuk kegiatan keserasian social selama ini dilaporkan meliputi kegiatan fisik dan non fisik.Kegiatan fisik seperti pembuatan jalan kampong, rehabilitasi sarana ibadah, pembuatan lapangan olah raga, rehabilitasi saluran air lingkungan, pengadaan air bersih, pembuatan sarana penerangan lingkungan dan pembuatan tugu keserasian social.

\section{B. Anak dan Keluarga Kasus Terorisme sebagai Kelompok Terstigmatisasi di Masyarakat}

Pengalaman dan cerita menghadapi stigma social di masyarakat banyak dialami oleh anak dan keluarga terduga, terdakwa, terpidana dan mantan narapidana kasus terorisme.Walaupun belum ada data yang valid tentang jumlah anak-anak teroris di Indonesia, baik yang orangtuanya ditahan maupun meninggal dunia, namun diprediksi anak-anak teroris itu mencapai lebih 2000 orang.Mereka hidup dalam kondisi yang memprihatinkan, ada yang terpaksa bekerja sebagai buruh anak, bahkan ada di antaranya yang putus sekolah.Tidak seharusnya anak-anak itu menanggung beban 'dosa' yang tak pernah mereka lakukan. Membiarkan mereka tentu saja merupakan pelanggaran HAM secara sistematis.Negara memiliki kewajiban untuk memberikan perlindungan terhadap mereka termasuk memenuhi hak mereka untuk mendapatkan akses pendidikan.

Munculnya cap buruk atau stigma negatif yang diberikan oleh orang lain atau lingkungan sosialnya dikhawatirkan akan sangat mengganggu kepribadian dan perilakunya. Sebagai contoh, cap: "Anak Teroris!" Pemberian label itu selain dapat meruntuhkan rasa percaya diri si anak, sang anak jadi minder, mudah tersinggung, atau juga bisa membuat anak terus-menerus dihantui rasa bersalah, yang sesungguhnya 
bukanlah tanggung jawab dirinya. Dampak negatif yang ekstrim bagi si anak, dia bisa nekat mewujudkan apa yang telah dilabelkan oleh lingkungan sosialnya pada dirinya itu.

Memberikan stigma negatif kepada mereka bukan hanya melanggar HAM akan tetapi merupakan bentuk kekerasan terhadap orang lain. Teori labeling tepat digunakan untuk pelaku kejahatan sebagai salah satu cara pengendalian sosial, tetapi bukan untuk keluarga terdakwa atau tersangka teroris. Mereka belum tentu tahu yang dilakukan ayah mereka di luar sana, tiba-tiba saja mereka mendapat cap "anak teroris" tentu bukanlah sesuatu yang adil. Padahal yang terjadi jika labeling dilakukan secara berlebihan dan tidak terkontrol maka sama saja kita membentuk teroris-teroris baru di masa depan.

Beberapa nama pelaku teror kelas kakap seperti Noordin M Top, Ali Imron, Amrozi, dan Imam Samudra, diketahui memiliki keturunan rata-rata lebih dari dua anak. Ketika akhirnya mereka dieksekusi mati, mau tidak mau keluarganya pun ikut terekspos, termasuk anak-anaknya.Sebagai konsekwensi dari pemberitaan media pada akhirnya masyarakat memberikan stigma negatif kepada keluarga dan anak pelaku teror tersebut.

Memberikan stigma dan bully terhadap anak terdakwa, terpidana atau manta teroris seperti: "eh, ada anak teroris..."; "dasar anak teroris"; "anak tukang bom!"; dan lain-lain merupakan bentuk dari labeling. Labeling adalah proses melabel seseorang. Menurut $A$ Handbook for The Study of Mental Health, label dapat dimaknai ketika diberikan pada seseorang akan menjadi identitas diri orang tersebut, dan menjelaskan orang dengan tipe bagaimanakah dia. Dengan memberikan label pada diri seseorang, kita cenderung melihat dia secara keseluruhan kepribadiannya, dan bukan pada perilakunya satu persatu. Dalam teori labeling ada satu pemikiran dasar, dimana pemikiran tersebut menyatakan "seseorang yang diberi label sebagai seseorang yang devian dan diperlakukan seperti orang yang devian akan menjadi devian".

Anak-anak ini tentu harus mendapatkan pendampingan dari semua pihak.Bentuk pendampingan harus dilakukan secara lebih moderat dan intens sehingga mereka secara perlahan dapat dijauhkan dari paham-paham radikal yang dilakukan oleh orang tuanya.Mereka perlu ditanamkan nilainilai kehidupan positif dan pengetahuan tegas bahwa terorisme adalah kejahatan yang tidak pantas dicontoh. Di sisi lain, perlu ada edukasi serupa terhadap masyarakat. Pemahaman yang benar mengenai nilai-nilai kemanusiaan dan perdamaian yang benar perlu ditanamkan sejak dini. Masyarakat perlu diberikan pemahaman tegas bahwa mereka tidak berhak untuk menghakimi orang lain apalagi memberikan stigma negatif, khususnya terhadap anak-anak pelaku teror yang tidak tahu apa-apa mengenai kesalahan orang tuanya. Kekerasan dalam berbagai wujud tidak pernah menyelesaikan persoalan, kecuali justru akan melahirkan bentuk kekerasan baru. Anak-anak harus diberikan bekal pemahaman nilai dasar kemanusiaan sejak dini, agar mata rantai kekerasan dapat terputus.

Salah satu contoh "kegalauan" yang diekspresikan dalam bentuk tulisan adalah sebuah novel kontroversial yang ditulis oleh Abidah el Khalieqy tentang Bagaimana rasanya menjadi 'istri teroris'? Novel ini mengangkat sudut pandang perempuan dalam isu terorisme. Abidah el Khaleqy kepada BBC Indonesia mengatakan novel berjudul 'Akulah Istri Teroris' pada intinya ingin mengangkat stigma negatif yang diterima para istri yang suaminya ditangkap karena dugaan terorisme. 
Stigma berasal dari bahasa Yunani yang artinya "tanda" atau "bercak". Pada zaman dulu merupakan tanda-tanda yang dimiliki seseorang pada tubuhnya berupa bekas bakaran atau torehan yang lain menandakan bahwa orang itu adalah budak, penjahat, atau pengkhianat. Ia adalah orang yang cacat moralnya dan karena itu harus dihindari, khususnya di tempat umum. Kata stigma juga dipergunakan dalam istilah stigma sosial, yaitu tanda bahwa seseorang dianggap ternoda dan karenanya mempunyai watak yang tercela, misalnya seorang bekas narapidana yang dianggap tidak layak dipercayai dan dihormati.

Aris Merdeka Sirait, mantan Sekretaris Jenderal Komnas Perlindungan Anak, pernah menyatakan bahwa anak-anak yang orangtuanya ditangkap polisi karena diduga terkait terorisme mempunyai hak dan kesempatan yang sama dengan anak-anak lain untuk tumbuh dan berkembang. Menurut Aris, anak-anak tidak boleh dikaitkan dengan keyakinan yang dipilih orangtuanya. Anakanak itu tidak tahu apa-apa tentang terorisme, termasuk juga perbuatan orangtuanya. "Peristiwa 1965 jangan terulang lagi. Dulu ada label anak PKI, jangan sampai sekarang muncul label anak teroris, sehingga terjadi diskriminasi. Perbuatan itu sama saja dengan menghilangkan Hak Asasi Manusia". 8

Asti Wulandari dari Fakultas Psikologi Unika Atmajaya Jakarta kepada Liputan6.com mengatakan bahwa anak-anak pada masa usia perkembangan (5-16 tahun) yang orang tuanya

\footnotetext{
${ }^{8}$ Aris Merdeka Sirait disarikan dari situs: http://news.liputan6.com/read/240331/jangancap-mereka-anak-teroris

${ }^{9}$ http://news.liputan6.com/read/240331/jangancap-mereka-anak-teroris
}

sedang mengalami kasus hukum (terorisme) perlu pendampingan khusus. Sedikit demi sedikit, secara bertahap anak diberikan pemahaman tentang persoalan yang sedang dihadapi orangtuanya sesuai dengan tingkat pemahaman si anak. Secara psikologis anak pada usia perkembangan seperti ini, amat gemar mengikuti model yang menjadi figur kekaguman dirinya. Bisa orang tua, sosok ayah atau ibu, atau tokoh personal orang lain di sekitarnya. ${ }^{9}$

Perlakuan dan penanganan terhadap anak-anak tak selalu bisa disamaratakan. Tapi paling tidak, menurut psikolog Asti Wulandari sedikitnya ada tiga hal yang bisa dilakukan untuk 'menyelamatkan' anak-anak itu. Pertama, edukasi terhadap masyarakat. Warga masyarakat harus paham benar, bahwa mereka atau siapa pun tidak berhak ikut menghakimi apalagi memberikan stigma negatif apa pun terhadap anak-anak para teroris. Kedua, anakanak dipindahkan ke lingkungan sosial yang baru.Tapi tempat yang baru pun, tak selalu tepat bagi anak. Karena kemungkinan akan memunculkan kembali masalah baru, di antaranya penyesuaian terhadap lingkungan sosial yang baru. Ketiga, memberikan pemahaman terus-menerus secara bertahap terhadap si anak tentang duduk persoalan yang dihadapi orangtuanya.Tentu saja dengan menyesuaikan kondisi mental dan tingkat pemahaman si anak. ${ }^{10}$

Semua pihak termasuk di dalamnya orang tua, guru, para tokoh agama, dan seluruh masyarakat, dan kalangan profesional harus

\footnotetext{
${ }^{10}$ Asti Wulandari, Jangan Cap Mereka Anak Teroris.

http://news.liputan6.com/read/240331/jangancap-mereka-anak-teroris
} 
menanamkan nilai-nilai kehidupan positif dan pengetahuan yang tegas kepada anak-anak: Terorisme itu adalah kejahatan yang tidak pantas dicontoh.

Sementara itu, Dr Tjipto Subadi MSi, dalam sebuah tulisannya di Harian Suara Karya mengatakan, seorang teroris anak dan juga anak teroris harus kembali dididik dengan pendidikan Islam yang benar dalam memahami makna jihad. Terlebih lagi, Indonesia dalam keadaan aman dan damai (darussalam) bukan dalam kondisi peperangan (darulharb) seperti Palestina, Irak, dan Afghanistan.Sehingga semangat jihad melawan orang kafir barat tidak berlaku di Indonesia.

Pendidikan seperti inilah yang harus ditanamkan kepada anak-anak sejak dini, agar mereka tidak terjerumus ke dalam semangat jihad yang keliru sehingga kelak pada hari kemudian menjadi teroris sebagaimana orangtuanya.Dengan demikian, seorang anak teroris harus dididik kembali untuk dimasukkan ke dalam sekolah khusus, agar pola berpikir mereka yang keliru dalam memahami agama bisa kembali benar.

Tjipto Subadi menambahkan, seharusnya pemerintah membentuk sekolah khusus tidak hanya bagi teroris anak dan anak teroris, tetapi juga para teroris yang telah selesai menjalani hukuman penjara akibat perbuatannya yang merugikan masyarakat, sekaligus mendiskreditkan Islam sebagai agama damai dan rahmatan lil alamin, seperti yang dilakukan pemerintahan Arab Saudi dan Mesir, sehingga mampu mengembalikan mereka ke tengah masyarakat dengan kehidupannya yang normal. ${ }^{11}$

\footnotetext{
${ }^{11}$ http://news.liputan6.com/read/240331/jangancap-mereka-anak-teroris
}

\section{Praktek Pekerjaan Sosialbagi Anak dan keluarga Terstigmatisasi Sosial karena Kasus Terorisme}

\begin{abstract}
Perserikatan Bangsa-Bangsa mendefinisikan terorisme:

"Criminal acts intended or calculated to provoke a state of terror in the general public, a group of persons or particular persons for political purposes are in any circumstance unjustifiable, whatever the considerations of a political, philosophical, idiological, racial, ethnic, religious or any other nature that may be invoked to justify them". ${ }^{12}$
\end{abstract}

\section{Sementara dalam Undang-Undang} Nomor 15 Tahun 2003 tentang Pemberantasan Tindak Pidana Terorisme, menjelaskan bahwa terorisme adalah perbuatan melawan hukum secara sistematis dengan maksud untuk menghancurkan kedaulatan bangsa dan negara dengan membahayakan bagi badan, nyawa, moral, harta benda dan kemerdekaan orang atau menimbulkan kerusakan umum atau suasana teror atau rasa takut terhadap obyekobyek vital yang strategis, kebutuhan pokok rakyat, lingkungan hidup, moral, peradaban, rahasia negara, kebudayaan, pendidikan,

\footnotetext{
${ }^{12}$ See http://www.un.org/documents/ga /res/49/a49r060.htm.
} 
perekonomian, idiologi, perindustrian, fasilitas umum, atau fasilitas internasional. ${ }^{13}$

Sedangkan inti dari pekerjaan social (social work) sebagaimana Global Definition of Social Work oleh International Federation of Social Worker (IFSW) pada Juli 2014 adalah sebagai berikut:

Social work is a practice-based profession and an academic discipline that promotes social change and development, social cohesion, and the empowerment and liberation of people. Principles of social justice, human rights, collective responsibility and respect for diversities are central to social work. Underpinned by theories of social work, social sciences, humanities and indigenous knowledge, social work engages people and structures to address life challenges and enhance wellbeing. "14

Selain itu, Zastrow mendefinisikan pekerjaan sosial sebagai sebuah aktivitas profesional dalam menolong individu, kelompok dan masyarakat dalam meningkatkan atau memperbaiki kapasitas mereka agar berfungsi secara sosial dan untuk menciptakan kondisi-kondisi masyarakat yang kondusif dalam mencapai tujuannya. ${ }^{15}$

Keberfungsian sosial (social functioning) oleh karenas itu menjadi ruh dalam praktek pekerjaan sosial.Pekerjaan social berusaha untuk memperbaiki, mempertahankan atau meningkatkan keberfungsian social orang, kelompok atau masyarakat.Menurut Bartlett (1970) yang dikutip oleh Prof. Adi Fahrudin (2012) menjelaskan keberfungsian social merupakan

\footnotetext{
${ }^{13} \mathrm{Abdul}$ Wahid, dkk, 2004. Kejahatan Terorisme Perspektif Agama, HAM dan Hukum. Bandung: PT Rafika Aditama hal. 29-30

${ }^{14}$ Global Definition of Social Work:

http://ifsw.org/policies/definition-of-social-work/
}

focus utama pekerjaan social.Keberfungsian adalah kemampuan mengatasi (coping) tuntutan (demand) lingkungan yang merupakan tugas-tugas kehidupan. Sedangkan Siporin (1975) menyatakan bahwa keberfungsian social merujuk pada cara individu-individu atau kolektivitas seperti keluarga, perkumpulan, komunitas, dan sebagainya -berperilaku untuk dapat melaksanakan tugas-tugas kehidupan mereka dan memenuhi kebutuhan-kebutuhan mereka. Karena orang berfungsi dalam arti perananperanan social mereka, maka keberfungsian social menunjukkan kegiatan-kegiatan yang dipandang pokok untuk pelaksanaan beberapa peranan yang karena keanggotaaanya dalam kelompok-kelompok social, setiap orang diminta untuk melakukannya.Singkatnya, menurut Siporin keberfungsian social menunjukkan keseimbangan pertukaran, kesesuaian, kecocokan, dan penyesuaian timbal balik antara orang, secara individual atau secara kolektif, dan lingkungan mereka (Adi Fahrudin, 2012:63).

Salah satu program yang menurut penulis layak diapresiasi adalah program pendampingan yang dijalankan oleh Prof. Sarlito beserta Tim dari Kepolisian Republik Indonesia bekerjasama dengan Lembaga Pemasyarakatan.Meskipun program ini sementara masih difokuskan kepada para istri narapidana kasus terorisme. Program yang dilakukan masih dalam level memberikan edukasi dan pendidikan deradikalisasi. Itu pun dalam prakteknya masih mengalami hambatan di antaranya tidak mendapat persetujuan dari para suami yang saat ini masih berada dalam lembaga pemasyarakatan.Hal ini terkait

\footnotetext{
${ }^{15}$ Sebagaimana dikutip oleh Miftahul Huda, 2013. IImu Kesejahteraan Sosial: Paradigma dan Teori. Yogyakarta: Penerbit Samudra Biru, ha. 5
} 
dengan izin suami yang tidak membolehkan bagi Tim untuk memberikan program pembinaan bagi para istri mereka.

Minimnya pelayanan sosial bagi anak terpidana kasus terorisme di Indonesia justru tanpa disadari akan memberikan kontribusi pada tumbuh suburnya penanaman nilai-nilai militanisme dan radikalisme dalam keluarga. Stigma sosial yang dilekatkan kepada anak teroris secara psikologis akan membekas dalam jiwa dan pikiran seorang anak. Anak menjadi "pendendam" dan memiliki resistensi yang tinggi terhadap orang lain. Perkembangan psikologis anak akan menutup diri, merasa bukan bagian dari masyarakat, merasa penyakit social, merasa harus menanggung beban social, dan sebagainya.

Padahal anak dan keluarga dari terdakwa, tersangka dan terpidana bahkan yang dieksekusi mati karena kasus teror meninggalkan anak istri yang tetap mempunyai hak hidup.Anak juga memiliki hak pendidikan yang lebih baik, anak harus diberi pemahaman tentang bahaya terorisme sebagai sebuah bentuk kejahatan yang tidak patut untuk dicontoh.

\section{Intervensi Berbasis Hak Asassi Manusia (HAM) dan Pendidikan multikultural}

Pekerjaan sosial adalah profesi pemberian bantuan untuk penyelesaian masalah, pemberdayaan dan mendorong perubahan sosial dalam interaksi manusia serta lingkungannya pada tingkat individu, keluarga, kelompok dan masyarakat untuk meningkatkan kesejahteraannya. Pekerjaan sosial mendasarkan intervensinya pada teori prilaku manusia dan lingkungan sosial serta prinsip-prinsip hak asasi manusia dan keadilan dengan memperhatikan faktor budaya masyarakat Indonesia (IFSW-IPPSI). ${ }^{16}$

The purpose of social work is "to (1) to enhance the problem solving and coping capacities of people, (2) link people with the systems that provide them with resources, services, and opportunities, (3) promote the effective and human operation of these systems, and (4) contribute to the development and improvement of social policy" (Pincus and Minahan, 1973, p.8)
${ }^{16}$ Definisi yang disepakati oleh Ikatan Pendidikan Pekerjaan Sosial Indonesia dan IFSW dan IPPSI 


\section{Social service sebagai ranah profesi peksos (Laksmono, 2013)}

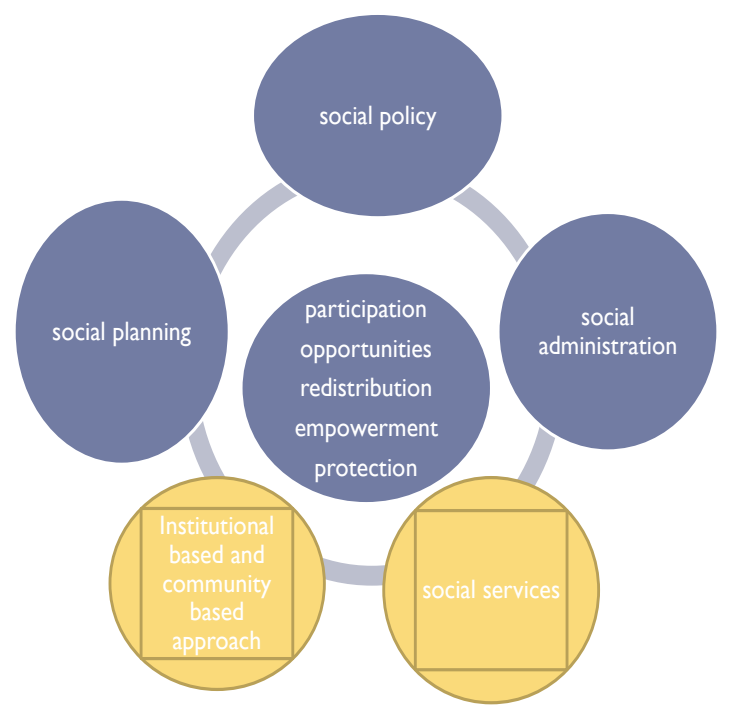

Dalam literatur pendidikan Ilmu Kesejahteraan/Pekerjaan sosial salah satu Mata Kuliah yang wajib diberikan kepada mahasiswa adalah tentang pendidikan Multikulturalisme, dengan berbagai nama mata kuliah seperti "pekerjaan sosial dalam masyarakat multikultural" dan lain-lain. Pendidikan multikultural sangat penting guna memberikan pemahaman bagi terwujudnya masyarakat multikultur dan terwujudnya keserasian sosial di masyarakat.

Sebagai dasar teori dari pendekatan berbasis HAM dan Pendidikan Multikultural adalah teori tentang pendekatan nondiskriminasi, pendekatan anti penindasan, teori system, teori attachment, teori psikodinamik, dan lain-lain.Praktik anti diskriminasi(anti discrimination)adalah praktik menentang tindakan diskriminatif yang berdasarkan ras, jender, jenis kelamin, disabilitas, orientasi seksual dan umur.Praktik anti penindasan (anti oppression) adalah praktik yang berfokus pada upaya melakukan efek-efek penindasan diskriminasi, di mana kelompok masyarakat yang memiliki kekuatan mempertahankan kekuasaanya dengan cara menciptakan stereotype yang negative. Pendekatan sensitive multicultural adalah pemikiran perbedaan budaya yang mengedepankan respon terhadap perbedaan budaya serta etnis yang ditemukan dalam masyarakat. 
Andersen dan Cusher ( 1994:320 ) menjelaskan bahwa pendidikan multikultural dapat diartikan sebagai pendidikan mengenai keragaman kebudayaan. Sebagaimana juga dijelaskan oleh James Banks ( 1993:3 ) bahwa pendidikan multikultural merupakan pendidikan untuk orang kulit hitam "people of colour". Artinya, pendidikan multikultural ingin mengeksplorasi perbedaan sebagai keniscayaan ( anugrah tuhan atau sunatullah ). Muhaemin el Ma'hady mendefinisikan pendidikan multikultural sebagai pendidikan tentang keragaman kebudayaan dalam meresponi perubahan demografi dan kultural lingkungan masyarakat tertentu bahkan dunia secara keseluruhan ( global ). Hilda Hernandez menjelaskan bahwa pendidikan multikultural sebagai prespektif yang mengakui realitas politik,sosial,dan ekonomi yang dialami oleh masing-masing individu dalam pertemuan manusia yang kompleks dan beragam secara kultur, dan merefleksikan pentingnya budaya, ras, seksualitas, agama, gender, etnisitas, status sosial, ekonomi, dan pengecualianpengecualian dalam proses pendidikan.

James Banks ( 1994 ), menjelaskan bahwa pendidikan multikultural memiliki beberapa dimensi yang saling berkaitan satu dengan yang lain, yaitu : (1) Content Intergration, mengintegrasikan berbagai budaya dan kerealisasi dan teori dalam mata pelajaran/disiplin ilmu; (2) the knowledge construction process, yaitu membawa siswa untuk memahami implikasi budaya ke dalam sebuah mata pelajaran ( disiplin ); (3) an equity paedagogy, yaitu menyesuaikan metode pengajaran dengan cara belajar siswa dalam rangka memfasilitasi prestasi akademik siswa yang beragam baik dari segi ras, budaya ataupun social; (4) prejudice reduction, yaitu mengidentifikasi karakteristik ras siswa dan menentukan metode pengajaran mereka.

Seseorang dapat menjadi pelaku terorisme dan berani melakukan tindakan radikal dipengaruhi oleh banyak faktor.Di antara beberapa faktor tersebut adalah faktor pemahaman agama, faktor diskriminasi atau kesenjangan sosial, faktor ekonomi, faktor balas dendam, kecemburuan sosial dan lainlain.Namun diantara semua faktor tersebut faktor yang paling dominan menjadikan seseorang melakukan tindakan teror, radikal dan kriminal adalah faktor idiologi.Tepatnya pemahaman agama yang salah dan berlebih (Prof. Asep Usman Ismail, Guru Besar Bidang Tasawuf UIN Syarif Hidayatullah Jakarta, 2016).

Pendapat ini tentu saja berbeda dengan pendapat yang disampaikan oleh Prof. Paulus Tandilintin, Guru Besar bidang Kesejahteraan Sosial/Pekerjaan Sosial yang menjelaskan bahwa seseorang dapat berubah menjadi radikal, menjadi jahat dan menjadi teroris itu bukan karena kesalahan orang tersebut semata. Akan tetapi karena faktor pendidikan atau sosialisasi yang salah (malsosialisasi) yang 
diterima oleh orang tersebut. Sederhananya seorang teroris itu menjadi teroris karena ia mendapat informasi dan sosialisasi dari orang lain bahwa menjadi teroris itu benar dan dibenarkan.

“.....Menurut saya orang itu tidak dilahirkan menyimpang! Orang menjadi menyimpang (menjadi teroris) itu pasti karena faktor lingkungannya. Jadi ...."kejahatan itu dipelajari!" .Kapan seseorang itu mulai salah? Ini pasti karena malsosialisasi. Apakah karena didikan? Apakah karena mendapatkan pengaruh dari media? Dan sebagainya yang saya kira saat ini semakin rumit urusannya apalagi setelah kebebasan media.Orang sudah saling mempengaruhi sudah di luar batas wilayah dan negara.Sebagaimana yang terjadi saat ini isu yang terjadi di sana (Arab) menjadi begitu berpengaruh di sini (pengikutnya ISIS, dll red.)". ${ }^{17}$

\section{E. Penutup}

Mewujudkan keserasian social di masyarakat dapat dilakukan oleh siapa saja termasuk oleh kita sebagai pekerja social.Diantaranya dengan melakukan pendampingan dan advokasi kebijakan dan program pelayanan social bagi kelompok terstigmatisasi social dari kalangan anak dan keluarga kasus terorisme.Praktek pekerjaan social berbasis HAM dan pendidikan multukultural.Oleh karena itu, sudah tepat jika seluruh penyelenggara pendidikan ilmu pekerjaan/kesejahteraan social dibawah naungan Ikatan Pendidikan Pekerjaan Sosial
Indonesia (IPPSI) untuk terus menjadikan mata kuliah pekerjaan social dalam masyarakat multikultur dan semua mata kuliah inti lainnya diberikan kepada mahasiswa.Aksi nyata dan pelayanan sosial yang paling konkret kita lakukan adalah dengan bekerjasama dengan Kementerian Sosial Republik Indonesia dalam mensukseskan program Keserasian Sosial di perguruan tinggi di mana kita bekerja. Diantara yang dapat kita usulkan adalah program bantuan beasiswa pendidikan bagi anak korban kekerasan social, anak korban pelaku kekerasan social atau kasus terorisme.Ini merupakan langkah konkret untuk memutus mata rantai terwariskannya benih-benih primordialisme, militanisme, dan radikalisme.Selain itu agar mereka kelak menjadi pribadi yang memiliki wawasan yang inklusif, moderat, dan memiliki jiwa yang setia terhadap Negara.

\section{DAFTAR BACAAN}

Ali, Mahrus. (2012). Hukum Pidana Terorisme Teori dan Praktik. Jakarta: Gramata Publishing (anggota IKAPI)

Antonowicz, D. H. \& Ross, R.R. (1994). Essential components of successful rehabilitation programs for offenders. International Journal of Offender and Comparative Criminology 38 (2): 97104. 25

Bjørgo, T. and Horgan, J. (Eds.) (2009). Leaving Terrorism Behind: Individual and Collective Disengagement. London: Routledge;

\footnotetext{
${ }^{17}$ Wawancara prof. Paulus
} 
Børgo \& Horgan (2009); Chowdhury Fink, N. \& Hearne, E.B. (2008). Beyond Terrorism: Deradicalization and disengagement from violent extremism. International Peace Institute.

Clear, T.R. \& Sumter, M.T. (2002). Prisoners, Prison, and Religion. Religion and Adjustment to Prison. Journal of Offender Rehabilitation, 35 (3/4).

Cullen \& Gendreau (2000); Cullen, F. T., \& Applegate, B. K. (1997). Offender rehabilitation: Effective correctional intervention. Aldershot, Hants, England: Ashgate, Dartmouth.

Cullen, F. T., \& Gendreau, P. (2000). Assessing correctional rehabilitation: Policy, practice, and prospects (pp. 109-175). In J. Horney (Ed.). National Institute of Justice criminal justice 2000: Changes in decision making and discretion in the criminal justice system. Washington, DC: Department of Justice, National Institute of Justice, p.114.

Dale, Orren, et. Al. (2006). Human Behavior and the Social Environment: Social System Theory. Library or Congres USA

Golose, Petrus Reinhard, Dr. (2009). Deradikalisasi Terorisme: Humanis, Soul Approach, dan Menyentuh Akar Rumput. Jakarta: Yayasan Pengembangan Kajian Ilmu Kepolisian.

Hasan, Noorhadi. (2010). Idiologi, Identitas dan Ekonomi Politik Kekerasan: Mencari Model Solusi Mengatasi Ancaman Radikalisme dan Terorisme di Indonesia. Majalah Prisma. Islam dan Dunia: Perjumpaan di Tengah Perbenturan. Vol. 29 Oktober 2010.

Hashmi, Arshi Saleem. (2009). Terrorism, Religious radicalism and Violence Perspectives from Pakistan. IPCS Issue Brief 121, September 2009

Hendropriyono, AM. (2013). Dari Terorisme sampai Konflik TNI-POLRI: Renungan dan Refleksi Menjaga Keutuhan NKRI. Jakarta: Kompas Gramedia.
Hendropriyono, AM (2009). Terorisme: Fundamentalis Kristen, Yahudi, Islam. Jakarta: PT Kompas Media Nusantara

Horgan, J. (2008). Deradicalization or disengagement? A Process in Need of Clarity and a Counterterrorism Initiative in Need of Evaluation. Perspectives on Terrorism, 2, 4.

Horgan, J. (2008). Deradicalization or disengagement? A Process in Need of Clarity and a Counterterrorism Initiative in Need of Evaluation. Perspectives on Terrorism, 2, 4.

Horgan, J. (2009). Walking Away from Terrorism: Accounts of Disengagement from Radical and Extremist Movements. London and New York: Routledge;

Horgan, J. and Braddock, K. (2010). 'Rehabilitating the Terrorists? Challenges in Assessing the Effectiveness of De-radicalization Programs.' Terrorism and Political Violence, 22 (1), 1-25;

Huda, Miftahul \& Hanjarwati, Astri. (2012). Interkoneksi Islam dan Kesejahteraan Sosial: Teori, Pendekatan dan Studi Kasus. Yogyakarta: Samudra Biru

Istiqomah, Milda. (2011). Deradicalization Program in Indonesian Prisons: Reformation on the Correctional Institution. University of Indonesia. Autralian Counter Terrorism Conference.

Kementerian Koordinator Bidang Politik, Hukum dan Keamanan, Republik Indonesia (2006), Kebijakan dan Strategi Nasional Pemberantasan Terorisme. Hal. 1-2.

Kementerian Koordinator Bidang Politik, Hukum, Dan Keamanan Republik Indonesia. (2009). Buku Petunjuk Deradikalisasi Terpadu. Jakarta.

Kementerian Pertahanan. (2003). Mempertahankan Tanah Air Memasuki Abad 21 (Buku Putih Pertahanan) 
Kruglanski, A. W., Gelfand, M. J., \& Gunaratna (2011). Aspects of deradicalization. In L. Rubin, R. Gunaratna, \& J. A. Gerard (Eds.), Terrorist Rehabilitation and counterradicalization. London: Routledge.

Kushner, Harvey W. (2003). Encyclopedia of Terrorism. London: Sage Publications. Laqueur, Walter. (1987). The Age of Terrorism. Boston: Little, Brown.

Muhammad, Afif. Prof. Dr. (2013). Agama dan Konflik Sosial: Studi Pengalaman Indonesia. Bandung: MARJA

Nelson-Jones, Richard. (2011). Teori dan Praktek Konseling dan Terapi. (edisi ke empat). Jakarta: Pustaka Pelajar

Neumann, P. (2010). Prisons and Terrorism: Radicalisation and de-radicalisation in 15 countries. London: The International Centre for the Study of Radicalisation and Political Violence.

Newman, W. Lawrence. (2006). Social Research Methods: Qualitative and Quantitative Approaches. Pearson International Edition.

O'Hare, Thomas. (2009). Essential Skills of Social Work Practice: Assessment, Intervention and Evaluation. Chicago, Illionis: Lyceum Books, Inc.

Pawson, R. \& Tilley, N. (1997). Realistic Evaluation. London: SAGE Publications;

Purwanto, Wawan H. (2011). One Decade of Terrorism in Indonesia. Jakarta: CMB Press.

Purwawidada, Fajar.(2014). Jaringan Baru Teroris Solo. Jakarta: Kepustakaan Populer Gramedia.

Rabasa, A., Pettyjohn, S.L., Ghez, J.J. \& Boucek, C. (2010). Deradicalizing Islamist Extremist. RAND Cooperation. Retrieved from: http://www.dtic.mil/cgibin/GetTRDoc?AD=ADA534160

Rapoport, David C. (2006). Terrorism: Critical Concepts in Political Science. United States Of America: Taylor and Francis.

Rappoport, A., Veldhuis, T.M., Guiora, A.N. Homeland Security and the Inmate Population: The Risk and Reality of Islamic Radicalization in Prison. In L. Gideon (Ed.) Special Needs of Offenders in Correctional Institutions. Thousand Oaks: SAGE Publishing (in press).

Ronald, Y. (2011). Social Work Intervention with Prisoners: The case of Varhad in Maharashtra. Rajagiri Journal of Social Development. Volume 3, Numbers 1\&2, December 2011

Rubbin \& Babbie. (2008). Research Methods for Social Work: 6th edition.

Solomon, A., Johnson, K., Travis, J. \& McBride, E. (2004). From Prison to Work: The employment dimensions of prisoner reentry: A report of the reentry roundtable. Washington, DC: Urban Institute.

Toseland, W. Ronald. (2001). An Introduction to Group Work Practice.4th edition.

Veldhuis, Tinka. (2012). Designing Rehabilitation and Reintegration Programmes for Violent Extremist Offenders: A Realist Approach.

International Crisis Group. (2007). "Deradikalisasi" dan Lembaga Pemasyarakatan di Indonesia. Asia report No 142-19 November 2007.

Kirst-Ashman, Karen, K \& Hull, Grafton, H.Jr. " Understanding Families" in "Understanding Generalist Practice". P.341-376 